\title{
Innovative Factors of Sustainable Development of Regions of Kazakhstan
}

\author{
Tatyana Sokira*, Zhanat Belgibayeva, Almazhan Dzhulaeva \\ Al-Farabi Kazakh National University, Almaty, Kazakhstan
}

\begin{abstract}
The article discusses the formation of a rating as a strategic planning tool in order to develop a set of measures to overcome regional inequality, equalize the levels of social-and-economic development and living standards of the population of the regions of Kazakhstan. Based on the data of the Committee on Statistics of the Ministry of National Economy of the Republic of Kazakhstan, indicators of region innovative developments of Kazakhstan were analyzed and calculated. The factors of the level of innovative activity are revealed. Based on them, groups of regions with a high, medium, below average and very low innovative development level were identified. There is a close relationship between the innovative development level and the rate of economic growth. On the one hand, the dynamics of economic growth requires innovation. On the other hand, innovation is the basis for increasing the competitiveness of the country and regions.
\end{abstract}

\section{Introduction}

In Kazakhstan, there is a differentiation in the innovative development level of regions, which is accompanied by negative trends in the form of migration from depressed to promising regions from an economic point of view, degradation of villages, uneven distribution of labor resources, polarization of income in prosperous and disadvantaged regions, differences in the standard of living of the population in territorial formations of the country.

The strategic plan for the development of the Republic of Kazakhstan until 2025 provides for the creation of strong regions and reduction of inequality between them as one of the seven areas of systemic breakthrough changes that should occur in the economy and social life of the country [1].

To develop strategic plans for the development of regions, determine measures for state support, and form clusters, first of all, information is needed that characterizes the current state of the regional economy, their inequality in the level of social-and-economic development.

It should be noted that such information may be contained in the ratings, which, given the heterogeneity of regional development, the presence of leaders and outsiders, allows not only assessing the positions of each territorial entity, but also determining the dynamics of regional development.

*Corresponding author: t_sokira@mail.ru 
Regional ratings represent an assessment of socio - economic development in each of them, which is important for business decision making in terms of investments, expansion of sales markets etc. [2].

Calculations of rating points are based on the data of the Committee on Statistics of the Ministry of National Economy of the Republic of Kazakhstan, which confirms their reliability, transparency and legality of use.

\section{Research Methodology}

Regions of Kazakhstan differ significantly in natural and climatic conditions, specialization, resource availability, innovative activity level and innovative development. For the successful implementation of the innovative scenario of the country's development, it is necessary to consider the regional characteristics, which make it possible to optimally link resources with the results, using the advantages of territorial entities.

In modern conditions, scientific research on the formation and functioning of regional innovation systems, clusters is given a special place, since the social-and-economic situation in the country and the life population quality depend on the efficiency of their functioning. Support for regional innovation systems is often seen as a tool to bridge the gap between developed and less developed regions of a country [3]. When companies are combined into a cluster, better results of competitiveness are achieved, information exchange becomes more diverse, multidimensional, intense and dynamic [4,5].

Pursuant to the next group of authors, the assessment of the priority of the formation of centers of innovative activity of various types in the regions is performed in two stages: at the first stage, a comparative assessment of the innovative capabilities of regions and the degree of development of industries of different technological levels in them is performed; their production and technological profile [6].

Meanwhile, various methods are proposed to assess the innovative development level of regions. Thus, V.N. Ryapukhina compares the coefficients of localization of results and resources of innovation activity, develops a matrix, which allows us to distinguish four groups of regions: 1) regions producing high innovative results based on high resources; 2) regions producing low innovative results with high potential for innovative activity; 3 ) regions producing low results of the innovation process with low resources; 4) regions producing high innovative results with low innovative resources [7].

Other authors distinguish 4 groups of factors of region innovative development: 1) scientific and technical potential, which covers the resources and results of the activities of research organizations and the creative potential of the population of the region; 2) production and technological potential, that is, the ability of enterprises and organizations in the region to introduce, disseminate and commercialize product, technological, organizational and marketing innovations; 3) the presence of a set of elements of the innovation infrastructure, including not only production and technology, but also information, financial, personnel and consulting components; 4) the nature of the innovation policy in the region (the mechanism of state and municipal management of the region innovative development, the regulatory framework, the volume of budgetary spending on science and innovation, protection of intellectual property) [8]. 


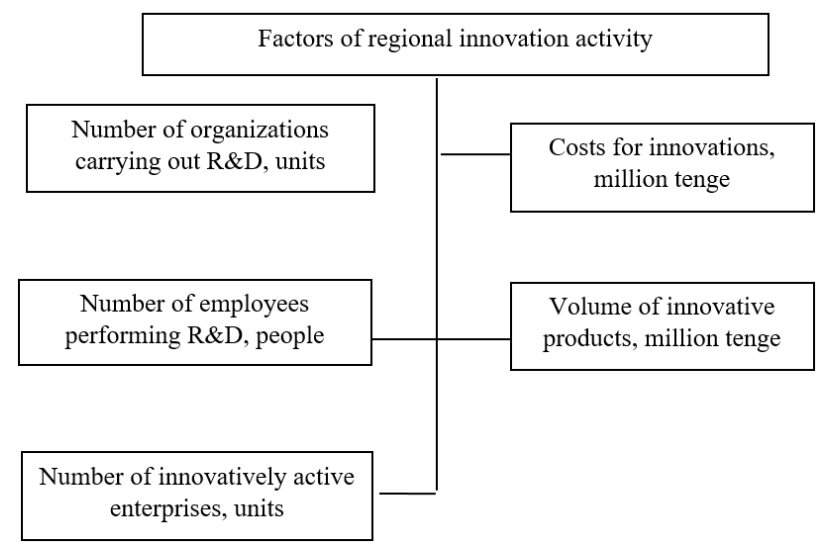

Fig. 1. Factors selected for the rating of innovative development of regions

To compile a rating of regions by the innovative development level, 5 factors were selected: the number of organizations employed in R\&D; the number of employees performing R\&D; the number of innovatively active enterprises; the cost of innovation and the volume of innovative products. The listed factors are quantitatively measurable, characterize both resource and productive aspects of the innovation process, reflect both innovative capabilities and the efficiency of innovation.

The calculations were performed step by step in the following logical sequence. At the first stage, the leader region is identified with the highest value of the indicator, which is taken as $100 \%$. Then, the corresponding parameters of the regions are determined as a percentage of the maximum value of the parameter of the leading region $[9,10]$.

$$
S i=\frac{X i}{X \max } * 100 \%
$$

Where, I - region number, $\mathrm{Xi}$ - parameter value for the i-th region; Xmax - maximum value of the parameter of the leading region; $\mathrm{Si}$-the percentage of the parameter value in the i-th region to the region - leader.

At the second stage, mathematical transformations are performed, which make it possible to calculate the final rating estimates of the region innovative development pursuant to the formula:

$$
A=(S a+S b+S c+S d+S e) / 5
$$

Where, A - rating assessment of the region's innovative development; $\mathrm{Sa}$ - the percentage of the number of organizations engaged in $\mathrm{R} \& \mathrm{D} ; \mathrm{Sb}$ - the percentage of the number of employees performing R\&D; Sc - the percentage of the number of innovatively active enterprises; $\mathrm{Sd}$ - percentage of innovation spending; $\mathrm{Se}$ - percentage of the volume of innovative products.

The rating assessment of the level of region innovative development is formed in the range from 0 to $100 \%$. The higher is the value of the final indicator, the higher is the rating of the region.

Table 1. Division of regions into groups pursuant to the innovative development level, depending on the rating score.

\begin{tabular}{|c|c|c|}
\hline Groups & Rating point, $\%$ & Value \\
\hline I & From 75 to 100 & High level \\
\hline II & From 50 to 75 & Average level \\
\hline III & From 25 to 50 & $\begin{array}{c}\text { Level lower than an } \\
\text { average }\end{array}$ \\
\hline
\end{tabular}




\begin{tabular}{|c|c|c|}
\hline IV & From 0 to 25 & Very low level \\
\hline
\end{tabular}

Table 1 identifies 4 groups of regions pursuant to the innovative development level: high level, average level, below average and very low level. Now, pursuant to the described methodology, we will proceed to the calculation of the necessary indicators, we will determine the ratings of the regions of Kazakhstan.

When conducting scientific research, the following methods were used: scientific abstraction, economic and statistical, induction and deduction, averages, economic groupings, analysis and synthesis.

Thus, the method of scientific abstraction revealed the patterns of innovative development, substantiated the relationship between innovative activity and the country's competitiveness. Analytical data were processed by economic and statistical methods, the parameters of the regions were calculated. The method of induction and deduction made it possible to formulate trends in innovative development on the basis of generalizations of single facts. When calculating the ratings, the average values of the factors under consideration were used. Regions with different levels of innovative development were identified using the method of economic groupings. The method of analysis and synthesis formed the basis of a systematic approach to the study of the characteristics and competitive advantages of the regions of Kazakhstan.

\section{Findings}

Before making calculations on the rating of innovative development, it is advisable to find out the range of variation between the analyzed indicators, since this directly affects the distribution of objects into groups.

Table 2 shows the maximum, average and minimum values of the factors of innovative development for 17 analyzed objects in Kazakhstan for 2019. The data presented indicate the presence of significant interregional differences between the levels of the indicators under consideration, which confirms the relevance of the rating assessment.

Table 2. Values of the values of factors of region innovative developments of Kazakhstan

\begin{tabular}{|c|c|c|}
\hline Indicator & \multicolumn{2}{|c|}{ Values, 2019} \\
\hline \multirow{3}{*}{$\begin{array}{c}\text { Number of organizations employed in R\&D, } \\
\text { units }\end{array}$} & Maximum & 138.0 \\
\hline & Average & 23.0 \\
\hline & Minimum & 5.0 \\
\hline \multirow{3}{*}{$\begin{array}{l}\text { Number of employees performing R\&D, } \\
\text { people }\end{array}$} & Maximum & $8,859.0$ \\
\hline & Average & $1,285.0$ \\
\hline & Minimum & 92.0 \\
\hline \multirow{3}{*}{$\begin{array}{c}\text { Number of innovatively active enterprises, } \\
\text { units }\end{array}$} & Maximum & 810.0 \\
\hline & Average & 189.0 \\
\hline & Minimum & 34.0 \\
\hline \multirow[t]{3}{*}{ Cost of innovation, KZT mln. } & Maximum & $91,664.7$ \\
\hline & Average & $32,061.54$ \\
\hline & Minimum & $4,482.1$ \\
\hline \multirow{3}{*}{$\begin{array}{l}\text { Volume of innovative products, } \\
\text { KZT mln. }\end{array}$} & Maximum & $223,618.8$ \\
\hline & Average & $65,503.91$ \\
\hline & Minimum & $7,536.3$ \\
\hline \multicolumn{3}{|c|}{ Note: based on the data of source [11] } \\
\hline
\end{tabular}

Thus, pursuant to the indicator of the number of organizations engaged in R\&D, the difference between the values of the maximum and minimum indicators is 27.6 times. Pursuant to the second indicator of the number of employees employed in R\&D, the maximum value reaches 8,859 people and the minimum value is 92 people. On average, one object accounts for 189 innovatively active enterprises. As for the costs of innovation, the 
discrepancy between the maximum and minimum values is more than 20 times. Finally, there is also a significant difference in the volume of innovative products.

Thus, it may be concluded that the analyzed objects are characterized by significant deviations from the average level, which indicates the unevenness of the region innovative developments of Kazakhstan, the need for a differentiated regional innovation policy.

Table 3. Distribution of analyzed objects of Kazakhstan in 2019 by groups of innovative development

\begin{tabular}{|c|c|c|c|c|c|}
\hline \multirow{2}{*}{ Indicators } & \multicolumn{4}{|c|}{ Groups } & $\begin{array}{c}\text { In } \\
\text { Kazakhsta } \\
\text { n }\end{array}$ \\
\cline { 2 - 6 } & I & II & III & IV & 17 \\
\hline Number of objects in a group, units & 1 & 1 & 3 & 12 & 386 \\
\hline $\begin{array}{c}\text { Number of organizations employed in } \\
\text { R\&D by group, units }\end{array}$ & 138 & 56 & 73 & 119 & 21,843 \\
\hline $\begin{array}{c}\text { Number of employees employed in } \\
\text { R\&D by group, people }\end{array}$ & 8,859 & 3,027 & 4,012 & 5,945 & 3,206 \\
\hline $\begin{array}{c}\text { Number of innovatively active } \\
\text { enterprises by group, units }\end{array}$ & 810 & 567 & 740 & 1,089 & 100.0 \\
\hline $\begin{array}{c}\text { Group share in innovation spending, \% } \\
\text { Group share in the volume of } \\
\text { innovative products, \% }\end{array}$ & 14.30 & 16.82 & 21.79 & 47.09 & 100.0 \\
\hline \multicolumn{2}{|c|}{ Note: calculated based on the data from source [11] } & 11.63 & 45.68 & 38.29 & \\
\hline
\end{tabular}

Table 3 shows that the first group, characterized by a high innovative development level, included one analyzed object - the city of Almaty, which may be explained by the fact that $35.75 \%$ of organizations employed in R\&D are concentrated in this city; employed $40.56 \%$ of employees performing R\&D; $25.65 \%$ of innovatively active enterprises operate; the group's share in spending on innovation was $14.30 \%$ and the group's share in the volume of innovative products was $4.40 \%$. The second group with an average innovative development level is represented by the city of Nur-Sultan. Here the number of organizations employed in R\&D was 56 units, the number of employees performing R\&D was 3,027 people, the number of innovatively active enterprises was 567 units. The group's share in spending on innovation reached $16.82 \%$ and the group's share in the volume of innovative products was $11.63 \%$.

The third group with a level of development below the average comprises 3 objects Karaganda, Kostanay and East Kazakhstan regions. The fourth group with a very low innovative development level is numerous, covering 12 objects: Shymkent, Akmola, Aktobe, Almaty, Atyrau, West Kazakhstan, Zhambyl, Kyzylorda, Mangistau, Turkestan, Pavlodar, North Kazakhstan regions.

As a result, the first group with a high innovative development level included $5.88 \%$ of objects, the second group with an average innovative development level also included $5.88 \%$ of objects, and the third group with a innovative development level below the average $17.64 \%$ and $70.60 \%$ respectively of objects formed the fourth group with a very low innovative development level.

As a result of the analysis, it was found that the shares in the volume of innovative products in the first and second groups noticeably lag behind the shares in the costs of innovation. In other words, the economic efficiency of innovation is low. In the third group, on the contrary, the share in the volume of innovative products is higher than the share in the costs of innovation. Hence, it follows that the regions of the third group are superior to other groups in terms of economic efficiency and recoupment of innovation costs.

Insufficient number of organizations and researchers engaged in $R \& D$, insufficient funding for scientific developments, underdevelopment of innovative infrastructure facilities, low level of support for regional authorities were the main reasons for low innovative 
activity. There is practically no such important attribute of local innovations as interaction between science, business and local authorities [12].

Thus, the results of the research performed make it possible to determine the ratings of the regions, identify the reasons for low innovation activity, substantiate the priorities of the formation of the innovation ecosystem in Kazakhstan, considering the characteristics and innovative development level of regional components. In this aspect, the leading regions have certain competitive advantages in terms of resource endowment, the availability of innovative infrastructure and the ability to implement the assigned tasks for sustainable development.

\section{Discussion}

In Kazakhstan, a comparison of regions will be performed on an ongoing basis in the form of a rating based on economic indicators and the results of business surveys. The main objective of the rating will be to stimulate competition between regions in terms of economic development, creating conditions for business, e.g., by ensuring connection to networks, access to land, and clear lines of action. The rating will be updated annually, published in the public domain, and on its basis the collection and dissemination of best practices between regions will be performed [1].

It should be noted that the rating of the regions of Kazakhstan performs informative, analytical, comparative, predictive and pragmatic functions. The first function is to inform stakeholders, government agencies, planners about the level of region innovative developments of Kazakhstan. With the analytical function, the diagnosis of the current state of the region is performed, the reasons for the low innovative activity are clarified. The comparative function identifies regions with high, medium, below average and very low levels of innovative development. The predictive function is associated with substantiating the prospects for the development of territorial entities, the need to implement an innovative development scenario that ensures higher rates of economic growth. The pragmatic function is to form a regional innovation policy, develop a set of measures to equalize the level of development of regions and enhance the social-and-economic situation in the country.

Rating assessments provide a visual representation of the innovative development level, the dynamics of the rating positions of regions with high, medium and low innovative activity, which is the basis for making management decisions to substantiate development priorities and enhance the efficiency of regional innovation systems.

\section{Conclusion}

In conclusion, it should be noted that the regional aspect of innovative development is very important for a country characterized by a large territorial length, low population density, the presence of various natural and climatic zones. The development of programs for the socialand-economic development of territories is based on a differentiated approach.

A differentiated approach, based on specialization, resource potential, the current state of the region's economy, makes it possible to substantiate the strategy of innovative development of each territorial entity, depending on the position in the rating structure.

In this aspect, the innovative scenario for the development of the country and its territorial entities allows in a shorter time to solve the problems of overcoming regional inequality, improving the life quality of all Kazakhstanis regardless of where they live.

\section{References}


1. Strategic development plan of the Republic of Kazakhstan until 2025. https://www.akorda.kz/ru/official_documents/strategies_and_programs

2. E.Yu. Makeeva, I. V. Ivashkovskaya, L.S. Ruzhanskaya, K.A. Popov, Economy of Region 17(1), 86 (2021). https://doi.org/10.17059/ekon.reg.2021-1-7

3. Review of the innovative development of Kazakhstan. UN. New York and Geneva, 205 pp. (2012).

4. V.V. Lizunov, National Priorities of Russia, 3(17), 97 (2015).

5. H. Fallah, S. Ibrahim, Knowledge spillover and innovation in technological clusters, Proceedings of the IAMOT Conference (2004).

6. I.M. Golova, A.F. Sukhovey, Economy of the Region, 15(4), 1294 (2019). https://doi.org/10.17059/2019-4-25

7. V.N. Ryapukhina, Issues of an innovative economy, 8(3), 391 (2018)

8. E.P. Garmashova, A.M. Drebot, Issues of Innovative Economics, 10 (3), 1523 (2020). doi: 10.18334 / vinec.10.3.110287.

9. A.B. Gusev, Science. Innovation. Education, 4(1), 158 (2009)

10. D.S. Musabalina, A.A. Kireeva, Economics: Strategy and Practice, 1(14), 149 (2019)

11. Science and innovation in Kazakhstan. Statistical collection. Nur-Sultan (2020)

12. F.M. Dnishev, Economics: strategy and practice, 1 (14), 71 (2019) 